\title{
Effects of reintubation on ventilator associated nosocomial pneumonias incidence in ICU patients with versus without selective digestive decontamination
}

\author{
AM Marrero-Rodríguez ${ }^{1 *}$, ER Argandoña-Primicia', ME Gallardo-Santos', P Juárez-San Juan ${ }^{1}$, CF Lübbe-Vazquez ${ }^{1}$, \\ JJ Díaz Díaz', P Saavedra², S Ruiz-Santana ${ }^{1}$
}

From ESICM LIVES 2015

Berlin, Germany. 3-7 October 2015

\section{Introduction}

Reintubation has been shown, among many others, to be an independent risk factor for development of ventilator-associated pneumonia ${ }_{1}$ (VAP) which is a major cause of morbidity and mortality in ICUs. Selective Digestive Decontamination (SDD) is a tool that prevent infections in critically ill patients particularly VAP, that has been used mainly in Holland and in Spain. Despite of the evidence its use remains controversial.

\section{Objectives}

To assess the VAP incidence after reintubation in patients admitted to a polyvalent ICU before and after starting a SDD program.

\section{Methods}

A retrospective study was conducted in a 30-bed-medicalsurgical ICU. We compared all patients admitted to ICU who required reintubation from October 2009 to October 2011 (non-SDD group) to those patients admitted to the ICU from October 2011 to October 2013, after starting a SDD program (SDD group) prospectively collected data. All patients that were expected to require tracheal intubation for longer than 48 hours were given SDD (SDD study group). Nosocomial infections were diagnosed by CDC criteria. In both groups, categorical variables were summarized as frequencies and percentages and the continuous ones as medians and interquartile ranges (IQR). The

${ }^{1}$ University Hospital of Gran Canaria Dr. Negrín, Intensive Care Unit, Las

Palmas de Gran Canaria, Spain

Full list of author information is available at the end of the article percentages were compared using the test of chi-square test or Fisher exact test and medians with the Wilcoxon test for independent samples. For VAP the incidences per 1000 days of mechanical ventilation were obtained. These rates were compared using the Poisson model. Statistical significance was set at $p \leq 0.05$.

\section{Results}

Results are shown in Figures 1, and 2. There was a nonsignificant reduction of VAP per 1000 days of mechanical ventilation ( 23.2 vs. 35.1$)$ in patients that were reintubated in the SDD period $(n=28)$ compared to those in the nonSDD period $(n=28)$. The risk reduction observed was $34 \%$.

\section{Conclusions}

There is a notorius reduction, towards significance in the incidence of VAP per 1000 days of mechanical ventilation in patients reintubated on SDD compared to those reintubated in the non-SDD period.

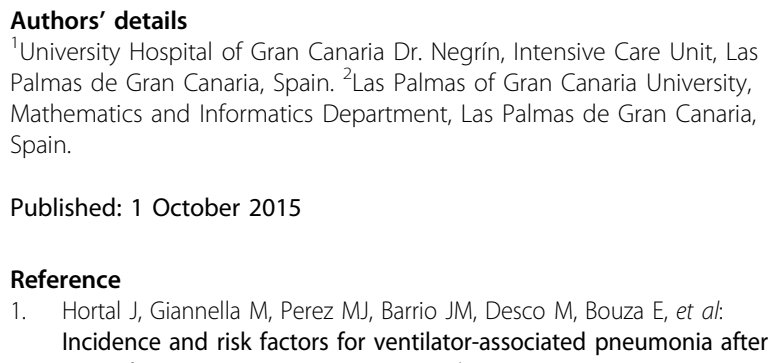

Published: 1 October 2015

Reference

1. Hortal J, Giannella M, Perez MJ, Barrio JM, Desco M, Bouza E, et al: Incidence and risk factors for ventilator-associated pneumonia after major heart surgery. Intensive care medicine 2009, 35(9):1518-25.

\section{SpringerOpen ${ }^{\circ}$}

(c) 2015 Marrero-Rodríguez et al.; This is an Open Access article distributed under the terms of the Creative Commons Attribution License (http://creativecommons.org/licenses/by/4.0), which permits unrestricted use, distribution, and reproduction in any medium, provided the original work is properly cited. 


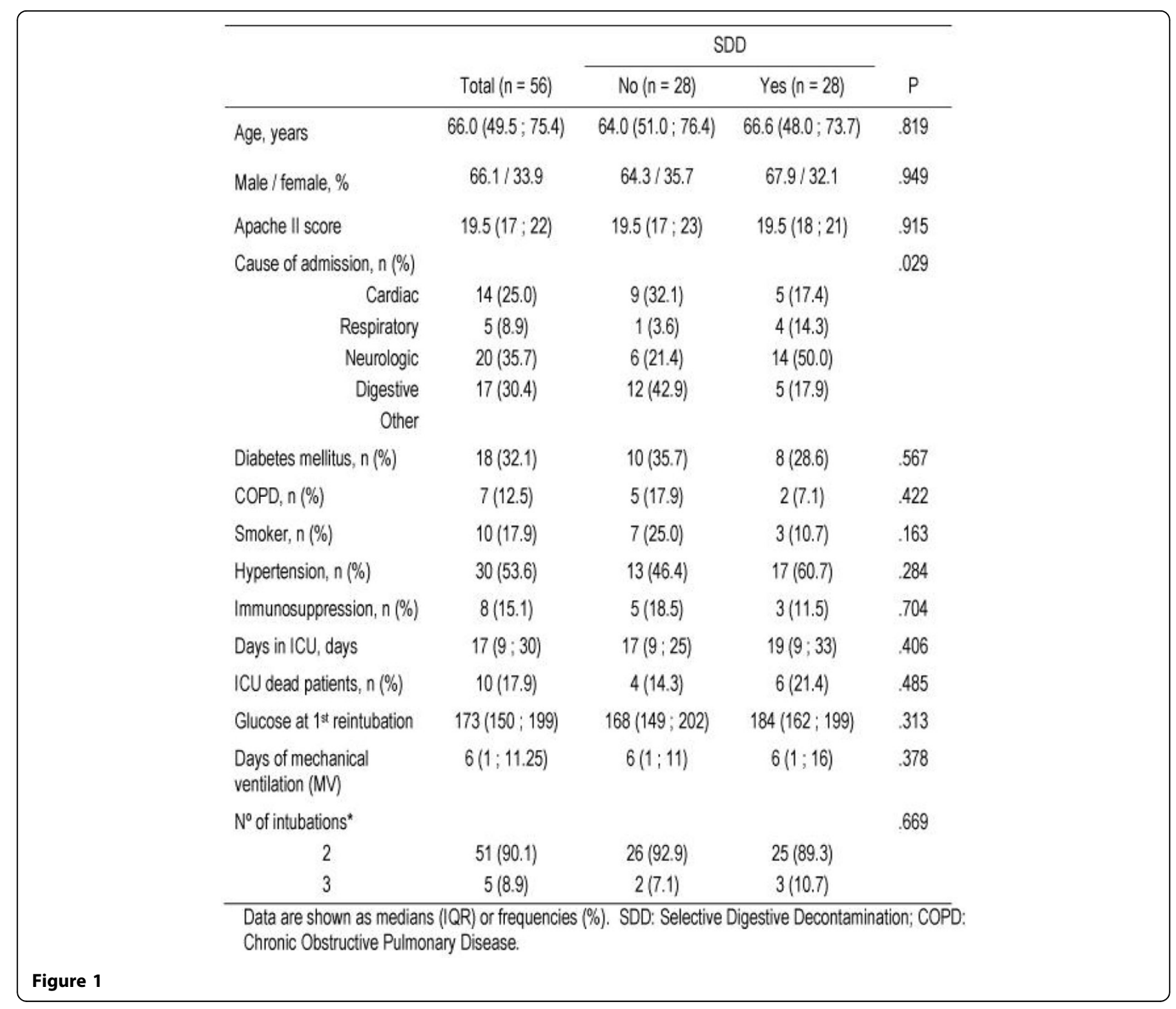

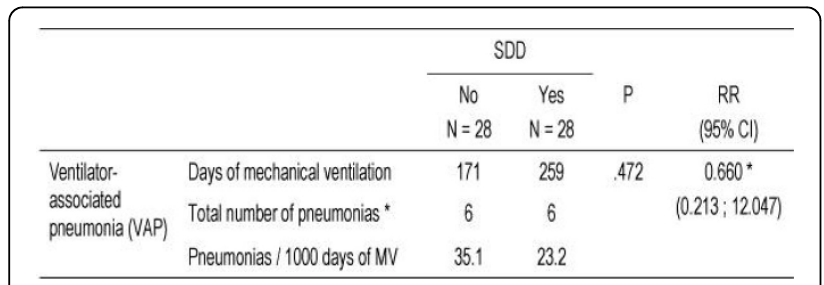

Figure 2

doi:10.1186/2197-425X-3-S1-A704

Cite this article as: Marrero-Rodríguez et al: Effects of reintubation on ventilator associated nosocomial pneumonias incidence in ICU patients with versus without selective digestive decontamination. Intensive Care Medicine Experimental 2015 3(Suppl 1):A704.
Submit your manuscript to a SpringerOpen ${ }^{\mathcal{O}}$ journal and benefit from:

- Convenient online submission

- Rigorous peer review

- Immediate publication on acceptance

- Open access: articles freely available online

- High visibility within the field

- Retaining the copyright to your article

Submit your next manuscript at $>$ springeropen.com 